\title{
EMPREENDIMENTOS URBANOS DE ECONOMIA SOLIDÁRIA: ALTERNATIVA DE EMPREGO OU POLÍTICA DE INSERÇÃO SOCIAL?
}

Com as transformações das sociedades capitalistas nas últimas décadas, impulsionadas pela internacionalização da produção e dos mercados e a chamada revolução da tecnologia da informação e comunicação - TICs, as mudanças nos processos produtivos e nas relações de trabalho visaram à diminuição de custos e aumento da produtividade. O trabalho, como elemento de inserção social e cidadania que caracterizou o período anterior, passou a ser repensado. Não que tenha perdido sua centralidade na vida social enquanto atividade que produz a subsistência, mas sua diversificação a partir dos novos processos produtivos, do questionamento de contratos de trabalho vinculados a direitos sociais que, para alguns, encareceriam a mercadoria força de trabalho, assim como a pulverização dos coletivos de trabalho, colocaram em xeque lutas coletivas e identidades sociais que marcaram as relações capital-trabalho por mais de um século. Tanto o capitalismo tinha no trabalho seu elemento de valorização, como o projeto de uma sociedade socialista alternativa tinha o trabalho como a referência de uma organização social controlada pelos trabalhadores.

Conceitos e proposições que salientam a situação de crise do fordismo, da sociedade salarial, da sociedade de bem-estar social, da pós-modernidade entre outros, que buscaram explicar essas mudanças, convergem na discussão sobre o que seria o esgotamento de um modelo de acumulação no qual o conflito de classes e o temor de uma sociedade socialista, gestaram um modelo de relações sociais marcado por conquistas dos trabalhadores relativas às condições de vida e trabalho.

O desmonte desse modelo caracterizou essas décadas. O fechamento de setores produtivos, o enxugamento na utilização da força de trabalho, o desemprego estrutural, o crescimento de relações de trabalho atípicas frente ao assalariamento, a informalidade, a mobilidade crescente dos capitais e da força de trabalho globalmente colocam novas questões sobre o trabalho, agora reconfigurado. Esta reconfiguração elimina uma estabilidade, mesmo que relativa, presente nos contratos por tempo indeterminado, na possibilidade de os trabalhadores terem uma carreira profissional, planejarem o futuro. Futuro que 
se tornou incerto pela instabilidade dos contratos temporários, pela ausência de contratos ou de formas alternativas que implicam a utilização da força de trabalho apenas quando necessária, desonerando o capital de mantê-la por longos períodos, mas também pelo enfraquecimento sindical decorrente da redução dos contingentes de trabalhadores e de sua desconcentração. Se a ameaça do século XIX estava nas multidões concentradas nas fábricas, essa mesma multidão, ainda que permanecendo nas cidades, está dispersa entre diversas atividades, com inserções diferenciadas no mercado de trabalho (Castells, 1999; Castel, 1998; Sennet, 2006).

Buscas por alternativas à falta de trabalho protegido ensejaram o surgimento de diversas propostas para proteger os sem trabalho. A própria utilização do conceito de trabalho passou a ser questionada a partir do conceito de atividade, que deveria garantir remuneração mínima a todos os trabalhadores. Formas alternativas de organização do trabalho e dessas atividades passaram a ser discutidas na Europa e América do Norte como modo de enfrentar essa crise. Uma série de empreendimentos de cunho coletivo, remunerados ou não, de caráter defensivo na proposta de manter empregos ou criar novos, foram pensados e, mesmo, implementados. Retomou-se o conceito de economia social, mas agora com outra perspectiva. Cooperativas de trabalho, de produção e outras se multiplicaram numa proposta diferente do chamado cooperativismo tradicional de mercado que se consolidou no século XX. Propostas de uma "outra economia" começaram a se estruturar, no que conhecemos hoje como economia social, economia solidária, economia popular (Singer, 2000; Coraggio, 2000, Quijano, 1998, 2002; Santos \& Rodriguez, 2002) juntando um conjunto de experiências diversas e mesmo díspares, mas marcadas pelo caráter coletivo e participativo de suas propostas.

No Brasil, este processo assume visibilidade na década de $1990 \mathrm{com}$ os efeitos da abertura e internacionalização econômica, dos processos de reconversão industrial e políticas de cunho neoliberal de desoneração do Estado. Uma série de empreendimentos alternativos organizados por ONGs, igrejas, universidades e sindicatos, tendo as cooperativas e associações de cunho coletivo e propostas de gestão democrática como modelo, foram implementados. A realização dos Fóruns Sociais Mundiais propiciou a formatação do movimento de economia solidária, cujas propostas foram sendo incorporadas como políticas sociais em diversos níveis de governo, culminando em 2003, com a criação da Secretaria Nacional de Economia Solidária (Senaes), que passou a mapear esses novos empreendimentos e suas características.

$\mathrm{Na}$ conformação de suas propostas, a economia solidária, procura demonstrar o caráter alternativo que o trabalho pode assumir a partir da propriedade e gestão coletivas por meio das quais os trabalhadores não apenas manteriam seus empregos, mas também a autonomia representada pelo processo participativo que pressupõe (Singer, 2000; Gaiger, 2003). Além da manutenção 
de empregos, tem-se também a organização de cooperativas e de associações formadas por trabalhadores excluídos do mercado, por questões de escolaridade, qualificação, faixa etária e gênero, para atuarem na prestação de serviços como coleta seletiva de lixo, reciclagem, costura, alimentação, artesanato e outras, que garantiriam, para os trabalhadores, não apenas renda, mas inclusão social. A partir da conformação de redes, esses empreendimentos conseguiriam sustentabilidade atuando em conjunto e paralelamente ao mercado. A economia solidária não se proporia a ser uma alternativa única ao capitalismo, mas plural, marcada pela convivência de mercados híbridos e na qual o trabalho se contraporia ao capital.

Nosso objetivo neste artigo é analisar o perfil desses empreendimentos buscando verificar como são organizados, seus indicadores de gestão participativa, sustentabilidade e suas possibilidades de garantir inserção social. Além disso, procuramos compreender também as principais tendências presentes nesse conjunto de associações e cooperativas, em que medida as redes solidárias se constituem, e até que ponto essas experiências correspondem à construção ideológica da proposta de economia solidária. ${ }^{1}$

O caráter múltiplo e fragmentário desses empreendimentos coloca várias questões, sendo a principal a própria definição do que se entende por organização de trabalho solidária num mercado caracterizado por seu oposto, ou seja, pela individualização crescente e pela cobrança de competitividade e menores custos. Em que medida a democratização presente na gestão coletiva responde a determinantes do mercado capitalista, que mesmo não sendo seu objetivo, é garantia da sustentabilidade dos empreendimentos? Outra questão que se pode colocar é a permanência na precariedade de empreendimentos voltados a uma população de baixa renda, de baixo capital cultural e escolar, que mantém esses trabalhadores com uma renda mínima de subsistência, comprometendo a continuidade das atividades e favorecendo seu abandono.

As questões são complexas e tentaremos, de forma preliminar, fazer algumas reflexões a partir dos dados produzidos pelo levantamento realizado pela Senaes. Assim, este estudo consiste em uma análise dos dados da base Sistema de Informação em Economia Solidária (Sies) de 2007 (único disponível, embora outro tenha sido realizado em 2009) sobre alguns aspectos relacionados à constituição, funcionamento e relacionamento externo dos empreendimentos urbanos de economia solidária.

\section{METODOLOGIA}

O Sies é um sistema de identificação e registro de informações dos empreendimentos econômicos solidários e das entidades de apoio, assessoria e fomento à economia solidária no Brasil que se orienta pelos conceitos constantes na 
Portaria do Ministério do Trabalho e Emprego, n 30, de 20 de março de 2006. Foi desenvolvido pela Secretaria Nacional de Economia Solidária do Ministério do Trabalho e Emprego e compreende o "o conjunto de atividades econômicas - de produção, distribuição, consumo, poupança e crédito - organizadas e realizadas solidariamente por trabalhadores e trabalhadoras sob a forma coletiva e autogestionária".

A base apresenta inúmeros problemas decorrentes da generalidade da definição de empreendimentos solidários utilizada, que inclui distintos tipos de cooperativas (de serviços, de comercialização, de consumo, de crédito etc.), associações e grupos informais envolvidos em atividades variadas, inclusive de caráter filantrópico, além de clubes e grupos de troca. Mesmo considerando os problemas presentes nessa base de dados, ela constitui um primeiro "quadro", e o único disponível até o momento acerca dos empreendimentos assim classificados.

Para a realização deste estudo foram priorizados os empreendimentos caracterizados pelo trabalho coletivo ou cooperativo dos seguintes subsetores econômicos: reciclagem, costura, calçado e alimentação. Também foram consideradas as fábricas recuperadas e associações/cooperativas de profissionais qualificados dos setores de engenharia, informática e educação. As fábricas foram separadas dos empreendimentos dos outros setores selecionados porque têm características muito diferenciadas quanto a sua constituição e funcionamento, além de predominarem em ramos industriais (metalurgia, plásticos, entre outros) não presentes de modo significativo nos demais empreendimentos caracterizados por trabalhadores excluídos do mercado de trabalho. No caso dos empreendimentos de profissionais qualificados selecionamos apenas os setores mais representativos presentes no levantamento desse extrato de trabalhadores.

O conjunto de empreendimentos cadastrados no Sies somava, em 2007, 21.859 organizações, das quais $48 \%$ estavam localizadas no meio rural, $34,5 \%$ no meio urbano, e as restantes com representação nos dois espaços, isto é, nos meios rural e urbano.

O primeiro critério para a seleção dos casos de interesse foi a "área de atuação do empreendimento". Selecionamos apenas aqueles empreendimentos que atuam em áreas urbanas. Ficamos, portanto, com apenas $34 \%$ dos casos da base original.

O segundo critério foi o tipo de atividade realizada. ${ }^{2}$ Selecionamos apenas os empreendimentos de produção e trabalho que declararam realizar a produção ou a prestação de serviço de forma coletiva. Com esses dois critérios, junto ao da área de atuação (meio urbano), restaram 6.281 casos ( $28,7 \%$ do total de empreendimentos cadastrados no Sies).

Finalmente, foram escolhidos alguns setores considerados representativos do tipo de trabalho desenvolvido por esses empreendimentos, como reciclagem, costura, alimentação, das fábricas recuperadas e dos profissionais qualificados nas áreas de engenharia e educação. Fechando a amostra apenas 
com os empreendimentos desses setores e estados selecionados, chegamos a um total de 3.821 , que correspondem a $60,8 \%$ dos empreendimentos urbanos que realizam trabalho coletivo.

O artigo está estruturado a partir de três eixos que consideramos ilustrativos da proposta de empreendimentos solidários, e seu funcionamento efetivo, em termos de participação dos trabalhadores e a percepção da proposta solidária, frente às questões objetivas do mercado de trabalho. Consideramos também, a partir dessas condições, a ampliação ou não do espaço político a partir da difusão do ideário solidário. Não houve a pretensão de analisar a economia solidária pelo negativo, ou seja, pela dissonância entre teoria e prática, mas, sim, o processo de construção da proposta, na ótica do trabalho e de suas possibilidades de se constituir em alternativa ao trabalho assalariado. Assim, começamos expondo os setores de atividade e as características assumidas por estas organizações, seguidas pelos critérios empregados para distribuição dos rendimentos entre os cooperados e, por fim, os relacionamentos e apoios externos destes empreendimentos.

\section{OS EMPREENDIMENTOS SOLIDÁRIOS}

Os empreendimentos selecionados totalizam 3.821 organizações com uma população de aproximadamente 120 mil trabalhadores (Tabela 1) [ver p. 125]. A costura é a principal atividade entre os empreendimentos selecionados, representando $57 \%$ do total, seguido dos setores de profissionais qualificados com $15 \%$, alimentação com $13 \%$ e reciclagem com $10 \%$. Os setores de costura, alimentação e reciclagem concentram a população-alvo do movimento e se distinguem pelo trabalho intensivo e pela histórica precariedade das relações de trabalho. Assim, mais que promover uma emancipação ou autonomia pelo trabalho, como em sua proposta original, a economia solidária, visa à inserção social de trabalhadores e trabalhadoras excluídos do mercado.

Esta característica aparece na própria composição por gênero desses trabalhadores, no qual as mulheres são predominantes, ao contrário da composição existente nas fábricas recuperadas e nas cooperativas de profissionais qualificados nas quais os trabalhadores associados são majoritariamente do sexo masculino. Nos setores ligados a habilidades tradicionalmente consideradas femininas e adquiridas no espaço doméstico, as sócias mulheres constituem, respectivamente, $77 \%$ (costura), $60 \%$ (alimentos). Na reciclagem de materiais e calçados, a presença de homens e mulheres é equilibrada, apesar de ainda predominarem as últimas, com, respectivamente, 53\% e 52\% (Gráfico 1) [ver p. 125].

As fábricas recuperadas, por sua vez, apresentam um retrato que reflete as dificuldades enfrentadas por diversos setores industriais no contexto de 
abertura econômica dos anos 1990, que resultou na ocupação de fábricas pelos trabalhadores e na formação da Associação Nacional de Trabalhadores em Empresas Autogestionárias (Anteag), em 1994. O número dessas empresas continuou a crescer, a partir da década de 2000 , inicialmente devido ao novo quadro institucional criado na esfera federal a partir de 2003, sendo que se estabilizou depois de 2007, com a recuperação econômica e com modificações na lei de falências que permitiu um novo fôlego às empresas em dificuldades financeiras.

O caso das associações e cooperativas de profissionais qualificados é diferente das demais em termos de extração social de seus trabalhadores, refletindo o crescimento do chamado terceiro setor, com a formação de cooperativas de profissionais liberais voltadas ao trabalho de assessorias e consultorias ao Estado, a movimentos sociais e mesmo para empresas que passaram a externalizar atividades mais especializadas. Nesses casos, essas associações respondiam, em geral, a propostas mais politizadas de seus integrantes, geralmente vinculadas a movimentos sociais diversos, nos quais a autonomia no trabalho se constituía num valor importante. ${ }^{3}$ Nestas associações, as mulheres são predominantes na área de educação que, tal como a costura e a alimentação, são consideradas atividades "femininas".

O tempo de existência destes empreendimentos pode ser tomado como um indicador da sustentabilidade e de inserção no mercado alternativo, se pensarmos em redes internas entre esses empreendimentos (feiras, cadeias produtivas etc.), no mercado representado pelos serviços e políticas governamentais, e mesmo no mercado capitalista, no qual, de uma forma ou de outra, todos se incluem. A maioria surgiu a partir do ano de 2000 , com uma forte expansão no período de 2003/2007 (51\%). Esse período reflete a expansão e institucionalização dos empreendimentos de economia solidária com a criação da Senaes pelo Governo Federal, o desenvolvimento de políticas públicas de geração de emprego e renda e a multiplicação de incubadoras de cooperativas em diversos municípios em todo o território nacional. Deve ser observado, entretanto, que nem todas as fábricas recuperadas ou associações se identificam como parte da economia solidária estando fora desse quadro. No caso das fábricas foi muito comum, no período em referência, a transferência de plantas para os trabalhadores pelos próprios proprietários, a permanência de hierarquias anteriores e a manutenção do mercado anterior, funcionando como uma empresa regular, trabalhando terceirizada para a empresa "mãe", ou mesmo para outras empresas. Outras situações, nessa direção, são as cooperativas formadas ou supervisionadas por empresas para terceirizar suas atividades (Lima, 2004) [ver p. 127].

Em todos os setores, o período 2003 a 2007 foi o de maior expansão desses empreendimentos, devido, como dito anteriormente, à mudança de governo e à implementação de politicas públicas tendo a economia solidária como fundamento. Esses números, entretanto, deixam de lado um dado importante, 


\begin{tabular}{l|l|l|l|l|l|l}
\multirow{2}{*}{$\begin{array}{l}\text { Setor de atividade } \\
\text { do projeto }\end{array}$} & \multicolumn{2}{l}{$\begin{array}{l}\text { Número de } \\
\text { empreendimentos }\end{array}$} & \multicolumn{4}{l}{ Número de sócios } \\
\cline { 2 - 7 } & $\mathrm{N}^{\circ}$ & $\%$ & Homens & Mulheres & Total & Total \% \\
\hline Reciclagem & 365 & 10 & 5169 & 5840 & 11.009 & $10 \%$ \\
\hline Costura & 2423 & 63 & 15458 & 53001 & 68.459 & $57 \%$ \\
\hline Calçado & 25 & 1 & 361 & 400 & 761 & $1 \%$ \\
\hline Profissionais Qualificados & 153 & 4 & 9195 & 7871 & 17.066 & $15 \%$ \\
\hline Alimentação & 767 & 20 & 6688 & 10054 & 16.742 & $13 \%$ \\
\hline Fábricas recuperadas & 88 & 2 & 3709 & 1854 & 5.563 & $4 \%$ \\
\hline Total & 3821 & 100 & 40580 & 79020 & 119.600 & $100 \%$
\end{tabular}

Tabela 1: Número de empreendimentos e distribuição dos sócios por setor econômico e gênero - Brasil Fonte: Sies (2007).

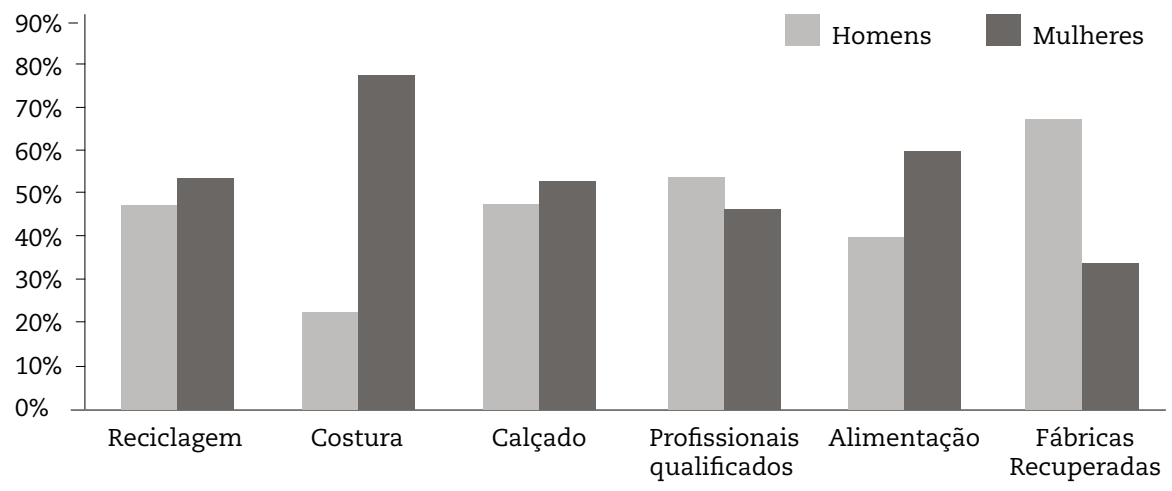

Gráfico 1: Distribuição dos sócios por setor de atividade e gênero - Brasil (\%) Fonte: Sies (2007). 
que é a mortalidade desses empreendimentos, similar às das micro e pequenas empresas, agravados, neste caso, pela dependência quanto à organização e manutenção do apoio de projetos estatais ou vinculados a ONGs, prefeituras municipais ou empresas que utilizam o apoio a cooperativas (principalmente nas de reciclagem), como forma de demonstrar sua responsabilidade social aos consumidores de seus produtos.

Apesar de as cooperativas de trabalho serem consideradas, inicialmente, como o modelo por excelência dos empreendimentos solidários, elas não constituem a forma dominante de organização da produção ou do trabalho. Em termos percentuais, são dominantes apenas nas fábricas recuperadas (68\%), resultantes de longos processos de ocupação, e significativas entre os profissionais qualificados ( $42 \%$ contra $47 \%$ que adotam outras formas), que, no geral, envolveram mais politização dos integrantes e participação na direção do empreendimento e mais autonomia no desenvolvimento do trabalho, indicando mais complexidade organizacional e capacidade de institucionalização.

Predominam, no universo selecionado, os chamados grupos informais, que, como o próprio nome diz, não envolvem muita institucionalização e apresentam grande instabilidade e precariedade, seja das condições de trabalho, da renda auferida e da capacidade de viabilização de sua produção. Os setores de costura e alimentação são majoritários nessa forma de organização. As associações, por sua vez, constituem a opção de parte importante dos empreendimentos, e sua forma mais antiga, independente se eles se constituem ou se assumem como empreendimentos solidários. No geral, sua inserção na economia solidária implica o convite de suas lideranças para participar de reuniões políticas e de formação técnica por meio das quais as associações passam a ter acesso aos processos de financiamento e formação promovida e ou apoiada pela Senaes.

A situação instável e precária de parcela significativa desses empreendimentos pode ser constatada quando se observa que quase metade deles não possui sede própria ou alugada, mas ocupam espaços cedidos ou emprestados. Somente as fábricas recuperadas apresentam uma situação mais favorável, totalizando $67 \%$ dos empreendimentos com imóvel próprio ou alugado [ver p. 127].

Na formação do campo da Economia solidária, o debate latino-americano não foi consensual na consideração da cooperativa como modelo organizacional. Coraggio (2000) se contrapõe a esse modelo propondo a pequena produção familiar como característica do que prefere chamar "economia popular". Posteriormente, tornou-se economia popular e solidária, economia social e solidária, ou simplesmente economia solidária, embora em países como a Espanha o termo mantido seja economia social. ${ }^{4}$

A ideia de economia dos setores populares vincula-se ao caráter e tamanho dos empreendimentos que, em sua maioria (53\%), possuem de um a dez 


\begin{tabular}{|c|c|c|c|c|c|c|c|}
\hline & \multicolumn{6}{|c|}{ Setor de atividade (\%) } & \multirow[b]{2}{*}{ Total } \\
\hline & Reciclagem & Costura & Calçado & $\begin{array}{l}\text { Profissionais } \\
\text { Qualificados }\end{array}$ & Alimentação & $\begin{array}{l}\text { Fábrica } \\
\text { recuperada }\end{array}$ & \\
\hline Até 1979 & 1 & 2 & - & 5 & 1 & - & 2 \\
\hline De 1980 a 1989 & 1 & 5 & & 10 & 4 & 3 & 4 \\
\hline De 1990 a 1994 & 3 & 4 & 4 & 10 & 4 & 7 & 5 \\
\hline De 1995 a 1999 & 16 & 13 & 32 & 22 & 13 & 30 & 14 \\
\hline De 2000 a 2002 & 33 & 22 & 12 & 22 & 23 & 30 & 23 \\
\hline De 2003 a 2007 & 45 & 54 & 48 & 28 & 54 & 31 & 51 \\
\hline Não respondeu & - & 1 & 4 & 2 & 0 & - & 1 \\
\hline Total (\%) $\left(\mathrm{N}^{\circ}\right)$ & $100(365)$ & $100(2423)$ & $100(25)$ & $100(153)$ & $100(767)$ & $100(88)$ & $100(3821)$ \\
\hline
\end{tabular}

Tabela 2: Empreendimentos segundo o ano do início de atividade e setor de atividade - Brasil (\%)

Fonte: Sies (2007).

\begin{tabular}{|c|c|c|c|c|c|c|c|}
\hline & \multicolumn{6}{|c|}{ Setor de atividade (\%) } & \multirow[b]{2}{*}{ Total } \\
\hline & Reciclagem & Costura & Calçado & $\begin{array}{l}\text { Profissionais } \\
\text { Qualificados }\end{array}$ & Alimentação & $\begin{array}{l}\text { Fábrica } \\
\text { recuperada }\end{array}$ & \\
\hline Grupo Informal & 45 & 71 & 36 & 20 & 73 & 22 & 65 \\
\hline Associação & 28 & 21 & 24 & 27 & 15 & 8 & 20 \\
\hline Cooperativa & 24 & 6 & 40 & 42 & 9 & 68 & 12 \\
\hline Sociedade Mercantil & 1 & 1 & & 8 & 4 & 2 & 2 \\
\hline Outra & 1 & - & - & 3 & 1 & - & 1 \\
\hline Total (N) & $100(365)$ & $100(2423)$ & $100(25)$ & 100 (153) & $100(767)$ & $100(88)$ & \begin{tabular}{|l}
100 \\
$(3821)$
\end{tabular} \\
\hline
\end{tabular}

Tabela 3: Setores de atividade selecionados segundo a forma de organização - Brasil (\%)

Fonte: Sies (2007). 
sócios. Esta faixa é mais representativa entre aqueles do setor de alimentos e costura, isto é, os setores mais tradicionais quanto ao uso de tecnologia, que exigem menos capital e são intensivos em trabalho. Por outro lado, as fábricas recuperadas possuem mais de $50 \%$ de empreendimentos nas faixas superiores (mais de 21 sócios por empreendimento), o que se explica, também, pela lei das cooperativas, que exige esse número de sócios para que o empreendimento seja registrado como tal. Mesmo nesses casos, deve-se destacar que as fábricas, em seu processo de recuperação, em geral perdem a maioria de seus trabalhadores que não conseguem permanecer, sem receber salários, até que o processo se resolva juridicamente. Tanto é assim que na maioria das fábricas recuperadas a faixa etária dos trabalhadores é alta (+ de 40 anos) e nem sempre se realiza facilmente o recrutamento de novos associados.

Constatamos que esses empreendimentos têm mantido certa estabilidade quanto ao número de sócios oscilando em percentual similar para cima e para baixo. Entretanto, os dados não oferecem indicações temporais mais detalhadas, o que nos permite inferir seu lento processo de estabilização que resulta na manutenção dos mesmos sócios. Mais uma vez, a faixa etária e a baixa qualificação/escolaridade dos sócios são fatores que podem explicar essa permanência [ver p. 129].

O rendimento médio mensal dos sócios reforça a observação de precariedade, na medida em que a grande maioria recebe (quando recebe) uma renda mensal abaixo do salário mínimo (90\%), sendo que $35 \%$ não têm nenhum rendimento. A ausência de rendimento indica o caráter embrionário dos empreendimentos ou objetivos não diretamente econômicos (se pensamos em atividades similares a terapias ocupacionais), dos que são vinculados a programas sociais, nos quais o rendimento pode vir a ser constituído, mas não obrigatoriamente. Isto também coloca em questão a constituição ou não de uma alternativa de trabalho ou de geração de renda, como os chamados serviços de proximidade (França \& Laville, 2004), cuidados, ou mais relacionados a trocas solidárias do que efetivamente a uma opção de rendimento.

Os rendimentos acima de dois salários mínimos acompanham a maior institucionalização dos empreendimentos, mas representam apenas $3 \%$ do total, embora alcancem $20 \%$ das fábricas recuperadas e $21 \%$ dos empreendimentos de profissionais qualificados [ver p. 129].

A remuneração, em certa medida, acompanha as características dos setores de atividades das cooperativas/empresas recuperadas, variando conforme a estrutura organizativa. Assim, nas cooperativas ou grupos informais de reciclagem, a remuneração por produto ou produtividade é significativa, embora a maioria dos empreendimentos paguem por horas trabalhadas. 0 mesmo acontece nas fábricas recuperadas e de profissionais qualificados. Nas fábricas de costura e alimentação, geralmente o pagamento é por produção, o que pode evidenciar o caráter de trabalho terceirizado, comum nesses setores, ou de encomendas intermitentes. Destaca-se, ainda, que esses dois setores 


\begin{tabular}{|c|c|c|c|c|c|c|c|}
\hline & \multicolumn{6}{|c|}{$\%$ - Setor de atividade do projeto } & \multirow[b]{2}{*}{ Total } \\
\hline & Reciclagem & Costura & Calçado & $\begin{array}{l}\text { Profissionais } \\
\text { Qualificados }\end{array}$ & Alimentação & $\begin{array}{l}\text { Fábrica } \\
\text { recuperada }\end{array}$ & \\
\hline 0 sócio & 1 & 1 & & & 1 & 1 & 1 \\
\hline De 1 a 10 sócios & 33 & 53 & 40 & 43 & 67 & 27 & 53 \\
\hline De 11 a 20 sócios & 31 & 19 & 12 & 17 & 13 & 10 & 19 \\
\hline De 21 a 50 sócios & 22 & 13 & 20 & 20 & 7 & 35 & 14 \\
\hline 51 ou mais sócios & 6 & 5 & 16 & 12 & 2 & 20 & 5 \\
\hline $\begin{array}{l}\text { Não declarou } \\
\text { ter sócios }\end{array}$ & 7 & 9 & 12 & 7 & 9 & 6 & 9 \\
\hline Total (N) & $100(365)$ & $100(2423)$ & $100(25)$ & $100(153)$ & $100(767)$ & $100(88)$ & $100(3821)$ \\
\hline
\end{tabular}

Tabela 4: Percentual de empreendimentos segundo a faixa de número de sócios e setores de atividade - Brasil Fonte: Sies (2007).

\begin{tabular}{|c|c|c|c|c|c|c|c|}
\hline & \multicolumn{6}{|c|}{$\%$ - Setor de atividade do projeto } & \multirow[b]{2}{*}{ Total } \\
\hline & Reciclagem & Costura & Calçado & $\begin{array}{l}\text { Profissionais } \\
\text { Qualificados }\end{array}$ & Alimentação & $\begin{array}{l}\text { Fábrica } \\
\text { recuperada }\end{array}$ & \\
\hline 0 salário mínimo & 23 & 37 & 16 & 37 & 35 & 17 & 35 \\
\hline $\begin{array}{l}\text { Até } 1 / 2 \text { salário } \\
\text { mínimo }\end{array}$ & 27 & 37 & 28 & 10 & 35 & 2 & 34 \\
\hline $\begin{array}{l}\text { De } 1 / 2 \text { a } 1 \text { salário } \\
\text { mínimo }\end{array}$ & 32 & 20 & 24 & 18 & 19 & 18 & 21 \\
\hline $\begin{array}{l}\text { De } 1 \text { a } 2 \text { salários } \\
\text { mínimos }\end{array}$ & 17 & 5 & 32 & 12 & 7 & 42 & 8 \\
\hline $\begin{array}{l}\text { De } 2 \text { a } 5 \text { salários } \\
\text { mínimos }\end{array}$ & 1 & 1 & - & 16 & 2 & 18 & 2 \\
\hline $\begin{array}{l}5 \text { salários } \\
\text { mínimos ou mais }\end{array}$ & 1 & 0 & - & 5 & 1 & 2 & 1 \\
\hline Total (N) & $100(365)$ & $100(2423)$ & $100(25)$ & $100(153)$ & $100(767)$ & $100(88)$ & $100(3821)$ \\
\hline
\end{tabular}

Tabela 5: Rendimento médio mensal dos sócios segundo os setores de atividade selecionados - Brasil Fonte: Sies (2007). 
também são os que mais apresentam dificuldades de remunerar o trabalho associado, não especificando, contudo, se recebem alguma forma de retribuição não monetária.

Esses dados devem ser vistos com cautela, uma vez que envolvem empreendimentos em organização e, dessa forma, sem nenhum rendimento, assim como trabalho voluntário, se pensarmos em trabalhadores mais qualificados. De qualquer forma, o conjunto dos dados indica problemas na garantia de uma renda mínima, que constitui um dos objetivos primordiais da proposta, e a dificuldade dos empreendimentos se manterem autonomamente.

\section{TRABALHADORES ASSOCIADOS E TRABALHADORES ASSALARIADOS}

Quanto à forma de inserção dos trabalhadores nos empreendimentos, o trabalho associado, ou seja, de trabalhadores não assalariados, mas associados a cooperativas ou associações, são dominantes. Nas fábricas recuperadas a situação é distinta em relação aos outros setores, pois $44 \%$ delas contratam assalariados. Os empreendimentos dos profissionais qualificados também apresentam uma quantidade significativa de não sócios (30\%), o que evidencia, além da maior complexidade organizacional, mais integração ao mercado e subordinação a seus ditames.

Pode-se inferir sobre o fechamento voluntário dos empreendimentos a novos sócios por considerarem problemática a entrada de trabalhadores desvinculados do processo de organização (na recuperação da fábrica ou da discussão inicial de formação da cooperativa) ou o desinteresse dos trabalhadores contratados em tornarem-se sócios, pois perderiam os direitos sociais vinculados ao assalariamento. É comum os sócios-trabalhadores das fábricas recuperadas reclamarem dos trabalhadores assalariados pela situação paradoxal, que em tese, enfrentam no chão de fábrica: como sócios, trabalham mais e têm menos direitos, uma vez que é rara a existência de fundos de reserva que lhes garantam retiradas regulares maiores que as auferidas pelos trabalhadores assalariados, sem contar as diferenças de responsabilidade entre eles [ver p. 131].

A contratação de trabalhadores não sócios indica, ainda, a presença de hierarquias internas e desigualdades na forma de inserção e participação dos trabalhadores nas decisões do empreendimento/cooperativa. Assim, se a contratação de trabalhadores externos pode indicar, de um lado, a expansão e consolidação do empreendimento, de outro permite questionar o seu caráter solidário e a adequação de seu modo de funcionamento aos princípios do cooperativismo e da autogestão.

Como observam Faria (2009) e Tauile \& Debaco (2002), as desigualdades entre os trabalhadores sócios e assalariados, que se expressam tanto na diferença de vínculos quanto na manutenção de hierarquias salariais e de co- 


\begin{tabular}{|c|c|c|c|c|c|c|c|}
\hline & \multicolumn{6}{|c|}{$\%$ - Setor de atividade do projeto } & \multirow[b]{2}{*}{ Total } \\
\hline & Reciclagem & Costura & Calçado & $\begin{array}{l}\text { Profissionais } \\
\text { Qualificados }\end{array}$ & Alimentação & $\begin{array}{l}\text { Fábrica } \\
\text { recuperada }\end{array}$ & \\
\hline Nenhum(a) & 86 & 89 & 84 & 73 & 86 & 57 & 87 \\
\hline De 1 a 10 trab. & 13 & 10 & 16 & 21 & 13 & 33 & 12 \\
\hline De 11 a 20 trab. & 0 & 0 & & 4 & 1 & 5 & 1 \\
\hline De 21 a 50 trab. & 1 & 0 & & 2 & 1 & 1 & 1 \\
\hline $\begin{array}{l}51 \text { ou mais } \\
\text { trabalhadores }\end{array}$ & 0 & 0 & - & 1 & - & 5 & 0 \\
\hline Total (N) & $100(365)$ & $100(2423)$ & $100(25)$ & $100(153)$ & $100(767)$ & $100(88)$ & $100(3821)$ \\
\hline
\end{tabular}

Tabela 6: Setores de atividade segundo o número de trabalhadores não sócios - Brasil Fonte: Sies (2007).

mando, inviabilizam a autogestão, na medida em que impedem a participação igualitária nos frutos do trabalho coletivo, na elaboração de alternativas e na tomada de decisões relativas à vida do empreendimento. A autogestão dessa forma é mais um valor a ser buscado do que efetivamente uma prática.

São poucas as fábricas e/outros empreendimentos que estabelecem a necessidade de todos os trabalhadores contratados tornarem-se associados. Isso, entretanto, ocorre em algumas fábricas que buscam manter a forte mobilização dos trabalhadores e os ideais de autogestão presentes na luta pela recuperação da fábrica, junto com as necessidades de expansão e de acompanhar o mercado no que respeita à tecnologia e formas de organização do trabalho. Com isso, temos experiências em andamento, as quais pressupõem que após três anos de contrato de trabalho o trabalhador se torne sócio, ou abandone o empreendimento (Oda, 2000; Leite, 2011), seguindo os passos da experiência de Mondragón, na Espanha, onde esta proposta tem orientado a relação entre sócios e contratados (White \& White, 1988) [ver p. 133].

\section{GESTÃO E PARTICIPAÇÃO}

As instâncias de direção dos empreendimentos existem em todos eles. Observa-se que a grande maioria possui assembleias ou reuniões de sócios, diretorias e conselhos fiscais, indicando a existência de mecanismos de participação assegurados e também alguma regulamentação da forma de gestão, pelo menos formalmente. Os setores de costura e alimentação fogem à regra geral quanto à existência de conselhos fiscais, talvez pela menor dimensão/institucionalização desses empreendimentos. De outra parte, somente as fábricas recuperadas 
e de profissionais qualificados apresentam uma proporção significativa com conselho administrativo, indicando, novamente, que existe uma proximidade entre esses dois setores quanto à forma de organização, mais envolvimento ou identificação com a proposta cooperativista, seja por serem constituídos por trabalhadores que participaram das lutas de recuperação das fábricas, adquirindo maior politização, seja por mais escolaridade e qualificação [ver p. 133].

Afirmam realizar assembleias com frequência mensal, quinzenal ou semanal, situação que nem sempre é observada quando se conhece esses empreendimentos. Os menores tendem a "informalizar" as reuniões coletivas por considerarem-nas desnecessárias dado o contato permanente entre os trabalhadores. No limite, isto termina implicando a captura, por alguns, do poder de direção, que se torna restritivo e excludente.

Os princípios da economia solidária incluem a participação democrática e ampla de todos os sócios do empreendimento/cooperativa nas decisões, incluindo a escolha dos que assumem as instâncias diretivas. A autogestão seria a forma de gestão e participação mais condizente e considerada por alguns autores como um dos elementos centrais que, conjuntamente com a propriedade coletiva do negócio pelos trabalhadores, diferenciaria esses empreendimentos das empresas capitalistas.

A autogestão, entretanto, pode ser percebida como um princípio a ser alcançado, mas raramente aplicado. O que existe são graus distintos de participação e democratização das atividades, como já observaram também Vietez \& Dal Ri (2001).

De acordo com os dados que analisamos, a maioria dos empreendimentos informa que os sócios têm acesso aos registros e informações do negócio e participam das principais decisões, incluindo eleição dos dirigentes, definição do plano de trabalho, destino das sobras e fundos e prestação de contas. As exceções ficam por conta dos setores de alimentação e dos profissionais qualificados, nos quais a participação dos sócios em algumas decisões como prestação de contas e, principalmente, contratação e remuneração só ocorre em uma porcentagem relativamente pequena dos empreendimentos. Cabe considerar, no entanto, que em muitos casos essa participação não significa possibilidade efetiva de influenciar nas decisões na medida em que as diferenças de escolaridade, qualificação ou de conhecimento sobre as questões relativas à gestão do negócio entre aqueles envolvidos na direção do empreendimento e o conjunto dos sócios faz com que estes últimos apenas concordem com proposições elaboradas alhures pelas lideranças. 


\begin{tabular}{|c|c|c|c|c|c|c|c|}
\hline & \multicolumn{6}{|c|}{$\%$ - Setor de atividade do projeto } & \multirow[b]{2}{*}{ Total } \\
\hline & Reciclagem & Costura & Calçado & $\begin{array}{l}\text { Profissionais } \\
\text { Qualificados }\end{array}$ & Alimentação & \begin{tabular}{|l|} 
Fábrica \\
recuperada
\end{tabular} & \\
\hline Sim & 14 & 11 & 16 & 30 & 14 & 44 & 14 \\
\hline Não & 86 & 89 & 84 & 70 & 86 & 56 & 86 \\
\hline Total $(\mathrm{N})$ & $100(365)$ & $100(2423)$ & $100(25)$ & 100 (153) & $100(767)$ & $100(88)$ & $100(3821)$ \\
\hline
\end{tabular}

Tabela 7: Setores de atividade segundo a contratação de trabalhadores não sócios - Brasil Fonte: Sies (2007).

\begin{tabular}{|c|c|c|c|c|c|c|c|}
\hline & \multicolumn{7}{|c|}{$\%$ - Setor de atividade do projeto } \\
\hline & Reciclagem & Costura & Calçado & $\begin{array}{l}\text { Profissionais } \\
\text { Qualificados }\end{array}$ & Alimentação & $\begin{array}{l}\text { Fábrica } \\
\text { recuperada }\end{array}$ & Total \\
\hline $\begin{array}{l}\text { Assembleia de } \\
\text { sócios(as) ou } \\
\text { reunião do coletivo } \\
\text { de sócios(as) }\end{array}$ & 73 & 63 & 96 & 79 & 64 & 80 & 65 \\
\hline $\begin{array}{l}\text { Diretoria/ } \\
\text { conselho diretor/ } \\
\text { coordenação }\end{array}$ & 59 & 37 & 60 & 60 & 31 & 65 & 40 \\
\hline $\begin{array}{l}\text { Conselho } \\
\text { Consultivo }\end{array}$ & 5 & 4 & 8 & 7 & 2 & 11 & 4 \\
\hline $\begin{array}{l}\text { Conselho } \\
\text { Administrativo }\end{array}$ & 19 & 10 & 52 & 42 & 9 & 61 & 13 \\
\hline Conselho Fiscal & 44 & 19 & 56 & 56 & 16 & 67 & 24 \\
\hline $\begin{array}{l}\text { Comissão ou } \\
\text { Conselho de Ética }\end{array}$ & 7 & 2 & 12 & 11 & 1 & 11 & 3 \\
\hline $\begin{array}{l}\text { Grupos de } \\
\text { Trabalho, } \\
\text { comissões ou } \\
\text { núcleos }\end{array}$ & 37 & 44 & 28 & 26 & 41 & 32 & 41 \\
\hline
\end{tabular}

Tabela 8: Setores de atividade segundo instâncias de direção do empreendimento - Brasil Fonte: Sies (2007). 


\section{ALTERNATIVAS AO DESEMPREGO E BENEFÍCIOS SOCIAIS}

Quanto à motivação que levou os trabalhadores a se associarem em empreendimentos de economia solidária, observa-se na Tabela 9 [ver p. 135] que o motivo predominante afirmado pelos trabalhadores foi a busca de uma alternativa ao desemprego. Somente para os trabalhadores das fábricas recuperadas e profissionais qualificados esta alternativa não é a mais importante. Entretanto, a utilização da categoria "recuperação por trabalhadores da empresa privada que faliu" é imprecisa, uma vez que mascara o caráter defensivo presente na recuperação das fábricas. A luta pela manutenção dos empregos explica a "recuperação". No caso dos profissionais qualificados, a diversificação decorre do caráter de prestação de serviços dessas associações e cooperativas, no geral vinculadas a propostas de intervenção política ou cultural.

O excedente e as sobras, quando existem, são geralmente distribuídos entre os sócios (em 21\% dos empreendimentos) ou vão para o Fundo de Reserva (em 19\% dos casos), como estabelecem as normas cooperativistas. Estes fundos garantem os investimentos na cooperativa/fábrica recuperada, assim como possibilita o pagamento de férias e outros benefícios aos sócios. Os fundos de investimentos aparecem em terceiro lugar (em 19\% dos casos) como destino das sobras. Esses fundos de investimentos provavelmente possibilitam algum rendimento aos fundos de reserva enquanto estes não são utilizados. Entretanto, a maioria dos empreendimentos, dado o nível de renda mínimo pago aos sócios, raramente consegue formar fundos de reserva, o que repercute diretamente na sua capacidade de oferecer alguns dos benefícios relativos aos direitos trabalhistas mínimos.

Assim, como pode ser visto na Tabela 10, apenas uma porcentagem muito pequena dos trabalhadores envolvidos nesses empreendimentos recebem algum tipo de benefício além da retirada mensal. Somente uma parte das fábricas recuperadas (30\% e $28 \%$, respectivamente) oferecem, descanso semanal e férias remuneradas, enquanto apenas $18 \%$ delas paga gratificação natalina, equivalente ao $13^{\circ}$ salário. Quanto aos benefícios que os trabalhadores recebem, somente as fábricas recuperadas oferecem, em apenas $30 \%$ dos empreendimentos, descanso semanal e férias remuneradas. Os benefícios-padrão da legislação trabalhista (CLT) não são concedidos ou, adaptados à condição de empresas coletivas. O mesmo acontece com programas de qualificação profissional e segurança no trabalho. Mais uma vez, são as fábricas recuperadas que buscam manter, talvez pela situação anterior, mais capitalização e certa cultura operária marcada pela presença dos direitos sociais vinculados ao trabalho [ver p. 137].

Quanto aos benefícios, o $13^{\circ}$ salário, ou gratificação natalina está presente em $12 \%$ dos empreendimentos de profissionais qualificados. Nos demais o percentual é ainda mais baixo, refletindo as dificuldades de formação e manutenção de fundos de reserva. As férias são mais comuns, embora não majo- 


\begin{tabular}{|c|c|c|c|c|c|c|c|}
\hline & \multicolumn{6}{|c|}{$\%$ - Setor de atividade do projeto } & \multirow[b]{2}{*}{ Total } \\
\hline & Reciclagem & Costura & Calçado & $\begin{array}{l}\text { Profissionais } \\
\text { Qualificados }\end{array}$ & Alimentação & \begin{tabular}{|l|}
$\begin{array}{l}\text { Fábrica } \\
\text { recuperada }\end{array}$ \\
\end{tabular} & \\
\hline $\begin{array}{l}\text { Uma alternativa } \\
\text { ao desemprego }\end{array}$ & 63 & 51 & 84 & 35 & 58 & 38 & 53 \\
\hline $\begin{array}{l}\text { Obter maiores } \\
\text { ganhos em um } \\
\text { empreendimento } \\
\text { associativo }\end{array}$ & 7 & 6 & 4 & 7 & 7 & 1 & 6 \\
\hline $\begin{array}{l}\text { Fonte complementar } \\
\text { de renda para os/as } \\
\text { associados/as }\end{array}$ & 7 & 18 & 4 & 8 & 17 & - & 16 \\
\hline $\begin{array}{l}\text { Desenvolver uma } \\
\text { atividade na qual } \\
\text { todos são donos }\end{array}$ & 6 & 5 & 4 & 14 & 5 & - & 5 \\
\hline $\begin{array}{l}\text { Condição exigida } \\
\text { para ter acesso a } \\
\text { financiamentos e } \\
\text { outros apoios }\end{array}$ & 1 & 2 & - & 3 & 1 & - & 1 \\
\hline $\begin{array}{l}\text { Recuperação por } \\
\text { trabalhadores de } \\
\text { empresa privada } \\
\text { que faliu }\end{array}$ & - & - & - & - & - & 59 & 1 \\
\hline $\begin{array}{l}\text { Motivação social, } \\
\text { filantrópica e } \\
\text { religiosa }\end{array}$ & 6 & 7 & & 12 & 5 & 1 & 6 \\
\hline $\begin{array}{l}\text { Desenvolvimento } \\
\text { comunitário de } \\
\text { capacidades e } \\
\text { potencialidades }\end{array}$ & 4 & 5 & 4 & 3 & 3 & - & 4 \\
\hline $\begin{array}{l}\text { Alternativa } \\
\text { organizativa } \\
\text { e de qualificação }\end{array}$ & 2 & 3 & - & 7 & 2 & - & 3 \\
\hline Outra. Qual? & 5 & 4 & & 12 & 1 & 1 & 4 \\
\hline Total (N) & $100(365)$ & $\begin{array}{l}100 \\
(2423)\end{array}$ & $100(25)$ & $100(153)$ & $100(767)$ & $100(88)$ & $\begin{array}{l}100 \\
(3821)\end{array}$ \\
\hline
\end{tabular}

Tabela 9: Setores de atividade segundo o motivo para a criação do empreendimento - Brasil

Fonte:Sies (2007). 
ritárias, pelo mesmo motivo. Também os profissionais mais qualificados e de empresas recuperadas têm mais acesso a esse benefício. A baixa presença deste benefício nos demais setores reflete, em grande medida, a precariedade das cooperativas e associações voltadas à inserção social com problemas permanentes de caixa.

Segundo Faria (2009), essas condições precárias têm atraído um conjunto de críticas à economia solidária. Para uma vertente, ela organiza cooperativas que são funcionais ao capital, ao disponibilizarem mão de obra barata, sem custos com direitos trabalhistas, que podem ser terceirizadas para empresas capitalistas, ou que produzem serviços baratos - como os realizados nas cooperativas de reciclagem, por exemplo -, contribuindo para a redução de custos dessas empresas. Outra vertente aponta para um programa cujo impacto sobre a geração de trabalho e renda é muito reduzido, já que uma parte importante dos empreendimentos (cerca de 30\%) não tem faturamento mensal e, portanto, não tem capacidade de remunerar os trabalhadores, enquanto a grande maioria dos que remuneram o fazem com valores muito reduzidos e até abaixo da média dos que recebem os menores rendimentos no conjunto da economia. Assim, se esses empreendimentos promovem inclusão, esta é "uma inclusão entre os excluídos", ou seja, entre os que não têm registro formal de trabalho, nem acesso a direitos, em atividades voltadas para a subsistência que estão à margem ou na periferia do sistema capitalista.

\section{RELACIONAMENTO EXTERNO}

Desde o primeiro mapeamento de fábricas recuperadas, realizado pela Anteag (2000), a preocupação com o relacionamento externo esteve presente. Isto pelo caráter da proposta de posse e gestão coletiva que, em grande medida, vai conformar a economia solidária. Nestas, o processo de autogestão implicaria ultrapassar os limites do processo produtivo, numa perspectiva de uma educação política voltada à transformação social.

Entretanto, a amplitude do mapeamento do Sies juntou empreendimentos diversos em sua formação, na qual o envolvimento com uma proposta autogestionária ou solidária nem sempre esteve presente, constituindo-se a posteriori. Com isso, o relacionamento externo esta mais presente com os órgãos de apoio do que propriamente a constituição de redes, ou mesmo de participação política mais abrangente dos membros participantes.

Grande parte dos empreendimentos recebe apoio substancial de organizações externas, sendo que em $32 \%$ deles esse apoio vem de organizações não governamentais, entidades religiosas e associações comunitárias, enquanto para outros - 31\% - ele é oferecido principalmente por órgãos governamentais. O sistema S, incluindo aí principalmente o Serviço Brasileiro de Apoio às Micro 


\begin{tabular}{|c|c|c|c|c|c|c|c|}
\hline & \multicolumn{7}{|c|}{$\%$ - Setor de atividade do projeto } \\
\hline & Reciclagem & Costura & Calçado & $\begin{array}{l}\text { Profissionais } \\
\text { Qualificados }\end{array}$ & Alimentação & $\begin{array}{l}\text { Fábrica } \\
\text { recuperada }\end{array}$ & Total \\
\hline Gratificação natalina & 7 & 2 & 0 & 12 & 3 & 18 & 3 \\
\hline Férias remuneradas & 7 & 1 & 4 & 14 & 2 & 28 & 3 \\
\hline $\begin{array}{l}\text { Descanso semanal } \\
\text { remunerado }\end{array}$ & 6 & 2 & 8 & 10 & 4 & 30 & 4 \\
\hline
\end{tabular}

Tabela 10: Setores de atividade segundo benefícios recebidos pelos sócios - Brasil Fonte: Sies (2007).

\begin{tabular}{|c|c|c|c|c|c|c|c|}
\hline & \multicolumn{7}{|c|}{$\%$ - Setor de atividade do projeto } \\
\hline & Reciclagem & Costura & Calçado & $\begin{array}{l}\text { Profissionais } \\
\text { Qualificados }\end{array}$ & Alimentação & $\begin{array}{l}\text { Fábrica } \\
\text { recuperada }\end{array}$ & Total \\
\hline $\begin{array}{l}\text { ONGs, OSCIPs, } \\
\text { igrejas, associações } \\
\text { e conselhos } \\
\text { comunitários }\end{array}$ & 40 & 29 & 24 & 29 & 39 & 28 & 32 \\
\hline $\begin{array}{l}\text { Órgãos } \\
\text { governamentais }\end{array}$ & 42 & 31 & 32 & 16 & 32 & 20 & 31 \\
\hline $\begin{array}{l}\text { Universidades, } \\
\text { incubadoras, } \\
\text { Unitrabalho }\end{array}$ & 21 & 8 & 8 & 15 & 11 & 16 & 11 \\
\hline $\begin{array}{l}\text { Sistema S (Sebrae, } \\
\text { Sesccop etc.) }\end{array}$ & 17 & 23 & 32 & 16 & 20 & 23 & 21 \\
\hline $\begin{array}{l}\text { Cooperativas de } \\
\text { técnicos(as) }\end{array}$ & 1 & 1 & 4 & 4 & 1 & 5 & 1 \\
\hline $\begin{array}{l}\text { Movimento Sindical } \\
\text { (Central, Sindicato, } \\
\text { Federação) }\end{array}$ & 5 & 2 & 4 & 4 & 2 & 18 & 3 \\
\hline Outra & 13 & 7 & 8 & 14 & 10 & 16 & 9 \\
\hline
\end{tabular}

Tabela 11: Setores de atividade segundo quem forneceu apoio ao empreendimento - Brasil Fonte: Sies 2007. 
e Pequenas Empresas (Sebrae) e o Serviço Nacional de Aprendizagem do Cooperativismo (Sescoop), tem, também, um papel importante no apoio a cerca de $21 \%$ das cooperativas e fábricas recuperadas. Dada a fragilidade organizativa da maioria desses empreendimentos, eles dependem, em grande medida, do suporte dessas instituições externas para assegurar a continuidade de suas atividades. No geral, são acompanhados no processo de sua formação e desenvolvimento por incubadoras responsáveis, em grande parte, pela construção do aparato administrativo, além de serviços técnicos e orientação política.

As incubadoras universitárias estão presentes em $11 \%$ do conjunto dos empreendimentos, com papel mais destacado na incubação das cooperativas de reciclagem (21\%), de profissionais qualificados (15\%) e de fábricas recuperadas (16\%) [ver p. 137].

Em grande medida esses apoios estão direcionados para as atividades de qualificação profissional (47\%), de assistência técnica ou gerencial (17\%) e de formação sociopolítica dos sócios, relativa, principalmente, aos princípios do cooperativismo, da autogestão e da economia solidária (20\%). Essas três linhas de atuação vinculam-se respectivamente aos processos produtivos, de gestão e formação política que caracterizariam o diferencial desses empreendimentos.

A participação em redes e fóruns de articulação está presente em $48 \%$ dos empreendimentos. A rede de economia solidária, fóruns e feiras são a alternativa mais frequente entre as opções listadas e que constituem o próprio cerne da formação do movimento de economia solidária, conforme ilustra a Tabela 12 [ver p. 139].

A maioria dos empreendimentos participa de fóruns de articulação devido à incubação vinculada a organizações não governamentais (ONGs), movimento sindical, incubadoras universitárias etc., que buscam mantê-los em suas redes de atuação. Os Fóruns de Economia Solidária são os que mais agregam os empreendimentos, talvez pela vinculação política com os órgãos incubadores. Nas Federações de Cooperativas, na qual é forte a presença da OCB (Organização das Cooperativas Brasileiras), apenas as de profissionais qualificados têm alguma participação mais significativa. As cooperativas de reciclagem, dada a natureza de sua atividade, participam mais de redes de produção e comercialização.

Entretanto, o número dos que não participam também é alto, refletindo problemas diversos, como desincubação por motivos políticos, desentendimentos com relação ao futuro do empreendimento e outros. Por exemplo, quando algumas cooperativas passam a terceirizar para empresas maiores, algumas incubadoras as abandonam. O mesmo ocorre quando a vinculação é a sindicatos ou centrais. Mudanças de concepção implicam abandono voluntário ou pelo órgão incubador.

O envolvimento em ações sociais está presente em $56 \%$ dos empreendimentos, ocorrendo, principalmente, nas áreas da educação, saúde e trabalho, 


\begin{tabular}{|c|c|c|c|c|c|c|c|}
\hline & \multicolumn{7}{|c|}{$\%$ - Setor de atividade do projeto } \\
\hline & Reciclagem & Costura & Calçado & $\begin{array}{l}\text { Profissionais } \\
\text { Qualificados }\end{array}$ & Alimentação & $\begin{array}{l}\text { Fábrica } \\
\text { recuperada }\end{array}$ & Total \\
\hline $\begin{array}{l}\text { Redes de produção/ } \\
\text { comercialização }\end{array}$ & 14 & 7 & 12 & 4 & 8 & 6 & 8 \\
\hline $\begin{array}{l}\text { Complexos } \\
\text { cooperativos }\end{array}$ & 2 & 1 & 4 & 8 & 1 & 8 & 1 \\
\hline $\begin{array}{l}\text { Federações de } \\
\text { cooperativas }\end{array}$ & 5 & 1 & 0 & 14 & 2 & 7 & 2 \\
\hline $\begin{array}{l}\text { Outras articulações } \\
\text { ou redes }\end{array}$ & 4 & 2 & 0 & 5 & 3 & 2 & 3 \\
\hline $\begin{array}{l}\text { Fórum ou Rede de } \\
\text { Economia Solidária }\end{array}$ & 28 & 24 & 8 & 16 & 33 & 25 & 26 \\
\hline $\begin{array}{l}\text { Centrais de } \\
\text { comercialização }\end{array}$ & 4 & 3 & 0 & 1 & 3 & 2 & 3 \\
\hline $\begin{array}{l}\text { Movimento social } \\
\text { ou sindical }\end{array}$ & 10 & 2 & 4 & 3 & 4 & 3 & 3 \\
\hline $\begin{array}{l}\text { Conselhos de gestão e } \\
\text { Fóruns de participação } \\
\text { em políticas }\end{array}$ & 2 & 3 & 0 & 3 & 3 & 2 & 3 \\
\hline $\begin{array}{l}\text { ONGs, Igrejas, } \\
\text { Pastorais, Fundações, } \\
\text { Sebrae, Universidades }\end{array}$ & 5 & 7 & 0 & 3 & 6 & 3 & 7 \\
\hline Outra & 6 & 3 & 0 & 7 & 4 & 5 & 4 \\
\hline
\end{tabular}

Tabela 12: Setores de atividade segundo a qual em rede ou fórum de articulação participa - Brasil Fonte: Sies 2007.

buscando manter o caráter de movimento presente na economia solidária. Esse envolvimento, contudo, restringe-se mais às direções das associações e das cooperativas do que efetivamente a seus membros.

A Tabela 13 [ver p. 141] aponta as ações sociais que fazem parte dos empreendimentos. Os dados são genéricos e imprecisos, pois misturam, em alguns casos, a própria atividade do empreendimento com as atividades dos órgãos de incubação, não permitindo maiores inferências sobre a efetividade da atuação social dos membros desses empreendimentos. Confrontando com pesquisas empíricas sobre fábricas, cooperativas e associações, percebe-se que a intensidade do trabalho presente na maioria delas pouco diferem de empresas regulares e, com isso, os trabalhadores associados, em sua maioria, estão fora de atividades políticas do movimento, restringindo a participação, como afirmado anteriormente, às lideranças. Essa mesma constatação foi feita por 
Kasmir (2007) ao analisar os trabalhadores de Mondragón e os limites da participação no gerenciamento do complexo.

\section{CONCLUSÕES}

Retomando as questões incialmente formuladas à luz da análise apresentada, verifica-se que os empreendimentos surgidos principalmente a partir do ano 2000 e vinculados à rede de economia solidária, apresentam um conjunto de características comuns, apesar de sua diversidade.

Em primeiro lugar, observa-se que a precariedade das formas de organização dos empreendimentos dos setores de costura, calçado, alimentação e reciclagem se manifesta na predominância dos grupos informais como forma de organização, nas dimensões reduzidas dos empreendimentos (maior porcentagem de empreendimentos na faixa de 1 a 10 sócios) e no tipo de infraestrutura: instalações provisórias com ocupação de locais cedidos por terceiros. Nas fábricas recuperadas e entre os profissionais qualificados, a tendência é de organização em cooperativa, portanto de maior formalização e aumento de número de associados.

Quanto à dimensão de gênero, é possível perceber que as mulheres predominam, nos setores de costura e alimentação, mas convivem com maior número de homens na reciclagem e no setor de calçados, enquanto os homens predominam nas fábricas recuperadas.

Em segundo lugar, os rendimentos recebidos pelos sócios(as) dos setores de costura, calçado, alimentação e reciclagem, na maioria dos casos são inferiores ao salário mínimo, situação agravada pelo fato de eles(as) não terem acesso aos benefícios-padrão da Consolidação das Leis do Trabalho (CLT). É pertinente observar a predominância feminina nos setores nos quais os rendimentos são muito baixos ou inexistentes. Essas constatações indicam as dificuldades existentes para que as trabalhadoras e trabalhadores se fixem nesses empreendimentos, ocasionando, em consequência, instabilidade e pouca probabilidade de consolidação e sobrevivência em longo prazo. Cabe ressaltar que, neste contexto, as empresas recuperadas e os empreendimentos dos profissionais qualificados estão em melhor situação, seja quanto ao patamar da remuneração dos seus associados (em cerca de $20 \%$ desses empreendimentos os rendimentos são maiores do que dois salários mínimos), seja quanto ao acesso a certos direitos trabalhistas, parecendo indicar melhor consolidação, bem como melhor adaptação dessas organizações às condições de mercado.

Quanto aos benefícios decorrentes do apoio do poder público, de entidades sindicais e não governamentais que poderiam minimizar os problemas anteriormente assinalados, cabe observar que, se de um lado, esse apoio está presente e pode ter sido decisivo na formação de parte significativa desses 


\begin{tabular}{|c|c|c|c|c|c|c|c|}
\hline & \multicolumn{7}{|c|}{$\%$ - Setor de atividade do projeto } \\
\hline & Reciclagem & Costura & Calçado & $\begin{array}{l}\text { Profissionais } \\
\text { Qualificados }\end{array}$ & Alimentação & $\begin{array}{l}\text { Fábrica } \\
\text { recuperada }\end{array}$ & Total \\
\hline Educação & 35 & 28 & 24 & 58 & 24 & 25 & 29 \\
\hline Saúde & 23 & 20 & 16 & 35 & 21 & 18 & 21 \\
\hline Moradia & 10 & 8 & 4 & 11 & 9 & 5 & 8 \\
\hline Trabalho & 27 & 26 & 28 & 29 & 26 & 20 & 26 \\
\hline $\begin{array}{l}\text { Redução da } \\
\text { violência }\end{array}$ & 13 & 12 & 12 & 22 & 11 & 5 & 12 \\
\hline Meio ambiente & 45 & 12 & 12 & 25 & 13 & 17 & 16 \\
\hline $\begin{array}{l}\text { Lazer/ esporte/ } \\
\text { cultura/ religião }\end{array}$ & 4 & 8 & 12 & 12 & 7 & 8 & 8 \\
\hline $\begin{array}{l}\text { Alimentação/ } \\
\text { doações/ } \\
\text { instituições/ } \\
\text { assistência social }\end{array}$ & 6 & 9 & 12 & 7 & 14 & 6 & 10 \\
\hline Outra & 4 & 3 & 0 & 1 & 3 & 2 & 3 \\
\hline
\end{tabular}

Tabela 13: Setores de atividade segundo a ação social que participa ou realiza- Brasil Fonte: Sies (2007).

empreendimentos, de outro ele não parece ser suficiente para melhorar as condições de vida dos associados e para garantir condições de expansão e sobrevivência dos empreendimentos.

De forma geral, os empreendimentos solidários respondem mais a políticas compensatórias do que efetivamente a uma alternativa ao emprego formal ou assalariado. Os empreendimentos indicam formas de organização dos processos produtivos, ou de coletivos de trabalhadores com relativa autonomia, dada a presença externa em sua organização e acompanhamento. Sua predominância em setores historicamente precários em termos de condições de trabalho, além de serem de baixa remuneração, concentrando trabalhadores pouco escolarizados ou qualificados, coloca a questão das possibilidades de mudanças nessa situação. Nas fábricas recuperadas o desafio é se manterem como cooperativas, ou pelo menos a busca de uma gestão coletiva mais efetiva frente às tendências de reconstrução de hierarquias e de participação cada vez mais formal. Isto em função dos determinantes do mercado, que tendem a integrar essas fábricas cooperativas em redes de suprimentos e de subcontratação. A utilização de trabalhadores não sócios também coloca o desafio do não fechamento da propriedade para um grupo de trabalhadores que tenderiam a 
se tornar proprietários e contratar assalariados, eliminando o caráter solidário do empreendimento.

Os valores de solidariedade permanecem sendo o maior desafio que podemos atribuir, talvez, ao caráter recente do movimento e da organização dos empreendimentos. O caráter híbrido da proposta talvez se mantenha, possibilitando a convivência da proposta com o mercado capitalista. A recuperação econômica do Brasil, nos últimos anos, a diminuição da informalidade e a retomada do crescimento, entretanto, mostram a dificuldade da proposta junto aos trabalhadores, constituindo-se mais em opção para aqueles que têm poucas opções frente ao mercado, trabalhadores jovens, idosos, mulheres, pouco escolarizados e qualificados.

A expansão de políticas sociais que têm como fundamento a economia solidária, pode se constituir numa opção ao assistencialismo histórico dessas políticas. Assim, mais do que alternativas de emprego, os empreendimentos terminam por funcionar como forma de inserção social, pela incorporação de trabalhadores excluídos do mercado em espaços produtivos e de discussão política, pelo investimento em formação técnica e associativa desses trabalhadores, que pode resultar em melhores possibilidades para esses mesmos trabalhadores de retorno ao mercado, ou de desenvolver alguma atividade que possibilite subsistência. Dessa forma, mais que alternativa ao trabalho assalariado, a proposta busca se constituir em alternativa à precariedade das condições de vida e trabalho para trabalhadores excluídos do mercado. A questão que permanece é como garantir a autonomia e viabilidade desses empreendimentos para que consigam sair da precariedade que, majoritariamente, os caracterizam. 
Jacob Carlos Lima é doutor em Sociologia pela Universidade de São Paulo (USP), professor titular do Departamento de Sociologia da Universidade Federal de São Carlos (UFSCar) e pesquisador do Conselho Nacional de Desenvolvimento Científico e Tecnológico (CNPq). Atua em pesquisas nas áreas de sociologia do trabalho, urbana, econômica e do desenvolvimento, destacando-se os temas: industrialização regional, redes sociais e mercados de trabalho urbanos, reestruturação produtiva, precarização do trabalho, entre outros.

\section{Angela Maria Carneiro Araújo é doutora em Ciências}

Sociais pela Universidade Estadual de Campinas (Unicamp), onde é professora e pesquisadora do Pagu - Núcleo de Estudos de Gênero, e pesquisadora do Conselho Nacional de Desenvolvimento Científico e Tecnológico (CNPq). Tem se dedicado aos seguintes temas de pesquisa: relações de gênero e trabalho, reestruturação produtiva, sindicalismo, cooperativismo e economia solidária.

Cecília Carmen Pontes Rodrigues é doutora em Ciências Sociais pela Universidade de São Paulo (USP) e pesquisadora do Centro de Estudos Rurais e Urbanos (Ceru), desta instituição, e do Centro de Estudos de Cultura Contemporânea (Cedec). Tem se dedicado aos seguintes temas de pesquisa: política em ciência e tecnologia, capital intelectual, gestão do conhecimento e sistemas de ensino a distância. 


\section{NOTAS}

1 Este texto é produto de pesquisa realizada nos dados do Sies e de seminários internos do projeto de pesquisa "A crise do trabalho e as novas formas de geração de emprego e renda. As distintas faces do trabalho associado, os trabalhadores e a questão de gênero", financiado pela Fapesp e pelo CNPq.

2 Segundo o Sies, os empreendimentos pesquisados desenvolviam as seguintes atividades: "produção de bens, de prestação de serviços, de fundos de crédito (cooperativas de crédito e os fundos rotativos populares), de comercialização (compra, venda e troca de insumos, produtos e serviços) e de consumo solidário".

3 Podemos incluir entre essas associações, a própria Anteag e outras associações que se tornaram os alicerces do movimento de economia solidária.

4 Sobre essa discussão no Brasil, ver Leite (2009).

\section{REFERÊNCIAS BIBLIOGRÁFICAS}

Anteag. Autogestão: construindo uma nova cultura de relações de trabalho. São Paulo: Anteag, 2000.

Castel, Robert. As metamorfoses da questão social: uma crônica do salário. Petrópolis: Vozes, 1998.

Castells, Manuel. A sociedade em rede. Rio de Janeiro: Paz e Terra, 1999.

Coraggio, José Luís. Da economia dos setores populares à economia do trabalho. In: Kraychete, Gabriel; Lara, Francisco \& Costa, Beatriz (orgs). Economia dos setores populares: entre a realidade e a utopia. Petrópolis: Editora Vozes, 2000, p. 91-131.

Faria, José Henrique de. Gestão participativa: relações de poder e de trabalho nas organizações. São Paulo: Atlas, 2009.

França Filho, Genauto \& Laville, Jean-Louis. Economia solidária: uma abordagem internacional. Porto Alegre: Ed. UFRGS, 2004. Gaiger, Luiz Inácio. Empreendimentos econômicos solidários. In: Cattani, Antonio David (org.). A outra economia. Porto Alegre: Veraz, 2003. 
Kasmir, Sharryn. O modelo Mondragón como discurso pós-fordista. In: Lima, Jacob Carlos (org.). Ligações perigosas: trabalho flexível e trabalho associado. São Paulo: Annablume, 2007. Leite, Márcia. Fábricas recuperadas e cooperativas de reciclagem: experiências no Estado de São Paulo. In: Georges, Isabel \& Leite, Márcia (orgs.). Economia solidária e novas configurações do trabalho. São Paulo: Annablume, 2011, p. 98-127. Lima, Jacob Carlos. O trabalho autogestionário em cooperativas de produção: o paradigma revisitado. Revista Brasileira de Ciências Sociais, 2004, 19/56, 2004, pp. 45-62.

Oda, Nilson. Sindicato e cooperativismo: os metalúrgicos do ABC e a Unisol Cooperativas. In: Singer, Paul \& Souza, André Ricardo (orgs.). A economia solidária no Brasil: a autogestão como resposta ao desemprego. São Paulo: Contexto, 2000, pp. 93-110.

Quijano, Aníbal. Sistemas alternativos de produção? In: Santos, Boaventura de Sousa (org.). Produzir para viver: os caminhos da produção não capitalista. Rio de Janeiro: Civilização Brasileira, 2002, p. 475-514.

La economia popular y sus caminos en América Latina. Lima: Mosca Azul Editores, 1998.

Santos, Boaventura de Sousa \& Rodriguez, César. Para ampliar o cânone da produção. In: Santos, Boaventura de Sousa (org.). Produzir para viver: os caminhos da produção não capitalista. Rio de Janeiro: Civilização Brasileira, 2002, p. 23-77.

Senett, Richard. A cultura do novo capitalismo. Rio de Janeiro: Record, 2006.

Singer, Paul. Economia solidária: um modo de produção e distribuição In: Singer, Paul \& Souza, André Ricardo (orgs). A economia solidária no Brasil. São Paulo: Editora Contexto, 2000, p. 11-28.

Tauile, José Ricardo \& Debaco, Eduardo. Autogestão no Brasil: a viabilidade econômica de empresas geridas por trabalhadores. Artigo apresentado no VII Encontro Nacional de Economia Política, Curitiba, 2002, mimeo.

Vietez, Candido \& Dal Ri, Neusa. Trabalho associado: cooperativas e empresas de autogestão. Rio de Janeiro: DP\&A Editora, 2001.

White, William Foote \& White, Kathleen. Mondragón: mas que una utopia. San Sebastian: Editorial Txertoa, 1988. 
Resumo:

Neste artigo buscamos analisar o perfil dos empreendimentos de economia solidária: como são organizados, seus indicadores de gestão participativa, suas condições de sustentabilidade e possibilidades de garantir inserção social de trabalhadores excluídos do mercado de trabalho. Consiste em uma análise dos dados de 2007 da base Sies (Sistema de Informação em Economia Solidária) do Ministério do Trabalho e Emprego. Procuramos verificar o que se entende por organização de trabalho solidário num mercado caracterizado por seu oposto, e em que a gestão coletiva se efetiva. Foram priorizados os empreendimentos caracterizados pelo trabalho coletivo ou cooperativo dos seguintes subsetores econômicos: reciclagem, costura, calçado e alimentação. Também foram consideradas as fábricas recuperadas e associações/cooperativas de profissionais qualificados dos setores de engenharia, informática e educação. Concluímos que, de forma geral, os empreendimentos solidários correspondem mais a políticas compensatórias do que efetivamente a uma alternativa ao emprego formal ou assalariado.
Palavras-chave:

Economia solidária;

Autogestão; Trabalho precário; Alternativa de inserção social; Sistema de Informação em Economia Solidária.

\section{Keywords:}

Solidarity economy; Self-management; Precarious work; Alternative of social inclusion; Information System of Solidarity Economy. 